\title{
Understanding Plant Blindness - Students' Inherent Interest of Plants in Higher Education
}

\author{
Sven Peter Batke ${ }^{1,}$, , Thom Dallimore ${ }^{1}$, John Bostock ${ }^{2}$ \\ ${ }^{1}$ Biology Department, Edge Hill University, Ormskirk, United Kingdom \\ ${ }^{2}$ Centre for Learning and Teaching, Edge Hill University, Ormskirk, United Kingdom \\ Email address: \\ sven.batke@edgehill.ac.uk (S. P. Batke), Dallimot@edgehill.ac.uk (T. Dallimore), Bostojo@edgehill.ac.uk (J. Bostock) \\ ${ }^{*}$ Corresponding author
}

To cite this article:

Sven Peter Batke, Thom Dallimore, John Bostock. Understanding Plant Blindness - Students' Inherent Interest of Plants in Higher Education. Journal of Plant Sciences. Vol. 8, No. 4, 2020, pp. 98-105. doi: 10.11648/j.jps.20200804.14

Received: August 7, 2020; Accepted: August 20, 2020; Published: August 31, 2020

\begin{abstract}
Plant-blindness' (PB) is the inability to see or notice plants in one's own environment. There has been growing concerns amongst biologists that PB is becoming an increasing issue in young university students. However, currently we are still lacking detailed quantitative data that would allow us to determine the exact underlying causes for this trend. In order to contribute to our understanding of PB, we aimed to quantify PB in undergraduate university students by deriving a PB score from face-toface quizzes. A total of 88 undergraduate students in Biology were surveyed. Students were more likely to correctly identify and recognize animals over plants in a series of picture tests. There was a weak positive correlation $\left(p=0.03, r^{2}=0.24\right)$ between the students' awareness of plants in their natural environment and their exposure to plant biology during pre-university schooling. Most students (65.9\%) believed that the inclusion of plants within university course contents increased their interest. Within this group, $30.6 \%$ indicated that because of this newly developed interest, they have chosen more relevant plant science modules. These results suggest that there is an inherent interest of plants in students surveyed in this study. However, this interest needs to be carefully nurtured throughout their educational progression. We proposed six areas to combat PB.
\end{abstract}

Keywords: Plants, People, University, Blindness

\section{Introduction}

"Plants look all the same" (Biology undergraduate student, 2019). The ability of people to perceive and differentiate individuals of the same/or different species, is a fundamental skill that enables people to define and categorise the world around them [1]. Many social constructs are built around the ability of people to differentiate between and notice organisms in their natural environment [2]. In recent years there has been a growing concern that people are losing their ability to recognize and correctly identify organisms, and the negative consequences this might have for wildlife conservation [3]. Many reasons have been proposed across the literature as to why, particularly younger people, are losing this ability. Interestingly, experimental research has shown that this loss is strongly biased towards plants. For example, Schussler and Olzak [4] conducted an experiment with college students in the U.S. to identify whether they could selectively recall more animal than plant images during an image sequence test. This study demonstrated that the students ability to recall images of animals was significant higher than those of plants, even when separated into specific university degree programmes (e.g. psychology versus botany) [4)]. The term 'plant-blindness' (PB) was coined by James H. Wandersee and Elisabeth E. Schussler [5] to neatly summaries the "inability to see or notice plants in one's own environment" [3].

Plant-blindness has mostly been attributed to perceptional, cultural and ethnographic factors such as the underrepresentation of plant related content in education [6], differences in people's visual perception between plants and animals [7], and differences in the exposure to plants at an early age. These factors could affect value-based perception towards plants [8]. Additionally, the need for knowledge about plants may be decreasing in today's societies as movement towards more specialized office-based ways of working reduces its inherent value. Increased urbanization, less access to nature, and an increasing loss of global biodiversity [9], is 
likely to have resulted in a physical distancing effect of plants from modern societies [10]. It is therefore not surprising that we are now seeing recorded increases in PB [11-13].

The exposure to, and development of, an interest towards plants at an early age can positively affect an individual's relationship towards plants and the natural environment [6]. In the UK, for instance, the school biology curriculum is very much biased towards a human and animal biology studies. For example, in years 4-6 of Stage 2 (age 8-11), there are no specific biology learning outcomes in the curriculum related to plants [14]. At Stage 3 (age 12-14), of the 39-government mandatory curriculum learning outcomes, only $9(23 \%)$ are directly related to plant related content [14-16]. At Stage 4 (15-16), this number is as low as $20 \%(9 / 45)$, and even then, of the $20-23 \%$ of plant related content taught at Stage 3 and $4,33-35 \%$ is primarily focused on the biochemistry of photosynthesis. Therefore, the removal of any photosynthesis content from the UK Stage 3 and 4 curricula, reduces the plant-based content taught in biology to approximately 14\% [14]. At Stage 5 (age 16-18), this trend continues, where most of the plant related teaching focuses again on plant photosynthesis [14]. This underrepresentation, and bias of content, taught in many UK schools is concerning, and has been highlighted by the UK Plant Science Federation [17]. It is, therefore, not unreasonable to hypothesise that the lack of plant based educational exposure has also contributed to the rise in $\mathrm{PB}$.

In 2018, within the UK's Higher Education (HE) system, biology degree programs were the third best recruiting subject disciplines after medicine and business. However, plant related courses are still less popular compared to other biology courses [18], and of the 164 universities and colleges in the UK, only 25 currently offer plant related programmes (2019/2020). Historically, recruitment figures have been relatively low but stable, as suggested by a report published in 2008 by The Centre for Education and Industry University of Warwick [19]; but detailed standardized data post-2008 is largely lacking. The UK is currently still recognized internationally for its leading excellence in plant sciences, however, this community will require the recruitment of younger people in the future, as currently, many skilled professionals are nearing retirement age. For example, only $4 \%$ of plant heath scientist, $5 \%$ of taxonomists and $5 \%$ of horticulturists in the UK are under the age of thirty [17]. Universities that offer plant related programmes and modules are challenged to overcome some of the above-mentioned obstacles to reverse the trend in PB, and to facilitate the recruitment of professionals into the plant science sector.

To do this effectively, data is required that can help explain the lack of interest in plants at a university level. Therefore, we developed three, research driven aims to contribute towards this outcome; (i) Quantify PB in undergraduate students by deriving a PB score for each student from a faceto-face quiz. (ii) Use a follow-up questionnaire to correlate the PB score to the students' experience of plant related content, at school, prior to University. (iii) Assess how their exposure to plant related content at university has affected their module choices in their final two years.
It is hoped that the data collected from this work will help $\mathrm{HE}$ institutes to better understand $\mathrm{PB}$, and therefore, improve our ability to better recruit more students into plant related programmes, and, or modules.

\section{Methodology}

\subsection{Plant-blindness Quiz and Questionnaire Design}

The project design had two main elements; a quiz and a follow-up questionnaire (Appendix 1). The quiz was designed to identify the participants 'degree' of 'plant-blindness' (PB). Four subscale questions were designed that tested the participants, a) basic species identification skills (Q3 a-d), b) organismal biases (Q1, Q4 \& Q7), c) how they prioritise organisms/structures in a landscape context (Q2, Q5 \& Q10), and d) general knowledge on organism interactions (Q6). All quiz questions included one or two images for the participants to view, before answering a question.

The questionnaire was designed to gather basic information about the participants with regards to preuniversity and post-school exposure to plants. This information was used during the analysis to identify possible relationships between the 'degree' of PB and the students' past experiences. Most of the questions where closed, with two open and one using a Likert scale.

\subsection{Ethical Considerations}

This project, the quiz and questionnaire have been approved by the Faculty of Arts and Science, Edge Hill University (EHU) ethics board for the academic year 2018/2019. Thus, all ethical considerations have been scrutinised under EHU's Code of Practice for the Conduct of Research [20].

\subsection{Data Collection}

The target group for this study were UK undergraduate biology students at level 4-6 (year 1-3). Participants were studying towards degree programmes in Biology, Ecology and Conservation, Human Biology, Genetics, Plant Science, Food Science and Biotechnology. The data collection took place between January and April 2019 at Edge Hill University. The quiz and the questionnaire (Appendix 1) were administered face-to-face at the end or beginning of lectures. Participants were first given the quiz, however, to remove answer bias, participants were not told of its purpose at this time. After the completion of the quiz, participants were informed by the lead researcher about the studies objectives and were given a consent form to sign. At this point, students who did not want to take part in the study, had the opportunity to opt-out. In the case were students opted-out, the completed quiz form was destroyed and not included in any further analysis. Students that chose to continue were then given the follow-up questionnaire. To ensure that the quiz and questionnaire results came from the same student, each student was allocated a unique but anonymous reference number. All survey data was digitised, and the original responses were archived within the 
Biology Department at Edge Hill University.

\subsection{Scoring the Quiz Questions and Calculating a 'Plant-Blindness'(PB) Score}

The PB score was calculated as the sum of all responsescores from the quiz, divided by the possible number of scores (=8.5). The PB score ranged from 0 to 1 , with 1 indicating a high 'awareness' of plants. A content analysis of the quiz was performed, and each question was scored based on the following criteria:

Question 1: A student was allocated a score of 0.75 when their response related to the tree in the picture rather than the squirrel. A score of 1 was only given when the tree was also correctly named (i.e. oak), otherwise the student received a score of 0 . In the case of multiple responses, only the first response was scored.

Question 2: When the answer referred specifically to the plants in the picture (e.g. ivy or a climber/vine) a student received a score of 1 . In the case where students gave an answer that was related to plants but did not specifically identify them (e.g. creeping or green), students received a score of 0.5 . If the answer referred to a building or structure in the picture (e.g. castle, house, abode or tower) the student received a score of 0 .

Question 3 (a-d): Students received 0.25 points for each correct identification. In the case of picture $3 \mathrm{~d}$, students only received 0.25 points if they specifically referred to the tree as a cherry tree. Answers such as 'blossom tree' was given a score of 0 .

Question 4: A student was allocated a score of 1 when their response related to the tree or the grassland in the picture rather than the lioness (or other feline species) that was sitting in the tree, otherwise the students received a score of 0 In the case of multiple responses, only the first response was scored.

Question 5: Answers that were specifically related to plants (e.g. flower, flowering, plants, botanicals or vegetation) received a score of 1 . For answers that were related to the manmade nature of the scenery (e.g. park, bird bath or fountain), students received a score of 0 . In the case were students used words such as 'outside', 'life', 'garden', 'park', 'scenery' or 'tranquillity', a score of 0.25 was given. In the case of the word 'nature', a score of 0.5 was given.

Question 6: As this question related to a specific plantinsect interaction, the maximum score that students were able to achieve was 0.5 . A score of 0.5 was given if the answer referred to any of the following actions; pollination, a bee collecting pollen, eating, nectar gathering or fertilisation. Instances where the answer inferred an action that was not shown in the picture but was implied by the action shown (e.g. making honey), a score of 0.25 was given. For other answers (e.g. the circle of life) a score of 0 was given.

Question 7: A student was allocated a score of 0.75 when their response related to the tree in the picture rather than the human climbing the tree. A score of 1 was only given when the response also identified the organisms name correctly (e.g. palm tree), otherwise the students received a score of 0 . In the case of multiple responses, only the first response was scored.

Question 8: A score of 1 was given when students specifically mentioned that the most striking difference between the pictures were absence/presence of plants or trees. When the word 'vegetation' or 'greenery' was used a score of 0.75 was given. A score of 0.5 was awarded for responses such as 'eco-friendly', 'biodiversity', 'landscape', and 'nature'. A score of 0 was given to all other answers (e.g. related to architecture and urbanisation).

Question 9: This question was not scored, as it was a dummy question.

Question 10: A score of 1 was given to answers such as 'plants', 'bushes', 'vegetation', 'foliage' and 'flower-wall'. A score of 0.5 was given to answers such as 'wildlife' and 'green area'. A score of 0 was given to answers such as 'soil', 'rocks', 'wall', 'building', 'boarder', 'shed' and 'fence'.

\subsection{Statistical Analysis}

Data was tested for normality prior to correlation or variance analysis, and a linear model was used to identify relationships between the mean $\mathrm{PB}$ score and the percentage of how much content (plant, animal or human) was covered in schools (pre-university). The PB score data did not require any data transformation, however, the percentage content data was logit transformed prior to analysis.

To test for differences of the PB scores between the sexes of the participants, an Analysis of Variance (ANOVA) was used. Additional comparisons were performed to test for differences between a) students that had a garden when they grew up, and those that did not, b) students whose parents have/had an interest in plants, and those students whose parents do/did not and c) students studying at different degree levels $(4,5$ and 6$)$.

Due to the low sample size, when dividing students into their different university programmes no additional quantitative analysis was performed to test for differences in responses between these groups. This was also the case for the different student age-classes, as $84 \%$ of students fell within the 17-21 age category.

All analysis were performed using the statistical software 'R' [21].

\section{Results}

A total of 88 undergraduate students were surveyed; 43 females, 39 males, and 6 that did not provide a specific gender identification. Of the 88 students, 40 were from level 4, 28 from level 5 and 20 from level 6 (Table 1). Seventyfour of the surveyed students were between the ages of 17-21, eight between the ages of 22-26, and five were above the age of 27. One student did not provide any age-related information.

The PB score showed no statistical differences between sexes (Table 2), or between students at different degree levels (Table 2); between students that had a garden when they 
grew up compared to those that did not (Table 2); and students that had parents that were interested in plants compared to those that did not (Table 2).

Table 1. Number of students surveyed across different degree levels and programmes.

\begin{tabular}{lll}
\hline Level & Programme & No. of students \\
\hline 4 & Biology & 12 \\
4 & Biotechnology & 5 \\
4 & Ecology and Conservation & 4 \\
4 & Genetics & 9 \\
4 & Human Biology & 7 \\
4 & Plant Science & 3 \\
5 & Biology & 6 \\
5 & Biotechnology & 13 \\
5 & Ecology and Conservation & 1 \\
5 & Genetics & 3 \\
5 & Human Biology & 5 \\
6 & Biology & 14 \\
6 & Ecology and Conservation & 2 \\
6 & Human Biology & 4 \\
Total & & 88 \\
\hline
\end{tabular}

Table 2. Comparison of the Plant-Blindness score between students of different sexes; between students that had a garden when they grew up, and those that did not; between students whose parents have an interest in plants and those that do not; and between different university levels (4, 5 and 6).

\begin{tabular}{llll}
\hline Variable & DF & t-value & p-value \\
\hline Sex & 85 & 0.527 & 0.619 \\
Garden & 86 & 0.094 & 0.926 \\
Parent interest & 86 & 0.814 & 0.418 \\
Year & 86 & -1.521 & 0.132 \\
\hline
\end{tabular}

The PB score did not correlate with the participants perception on whether their teacher at school was enthusiastic about plants $\left(\mathrm{t}=-0.152, \mathrm{p}=0.880, \mathrm{r}^{2}=-0.011\right)$. However, we found that the PB score had a weak-positive correlation with the percentage of plant biology taught at school (Figure 1). In addition, the PB score had a weaknegative correlation with the percentage of human biology taught at school (Figure 1). The correlation between the PB score and the percentage of animal biology taught at school was non-significant (Figure 1).
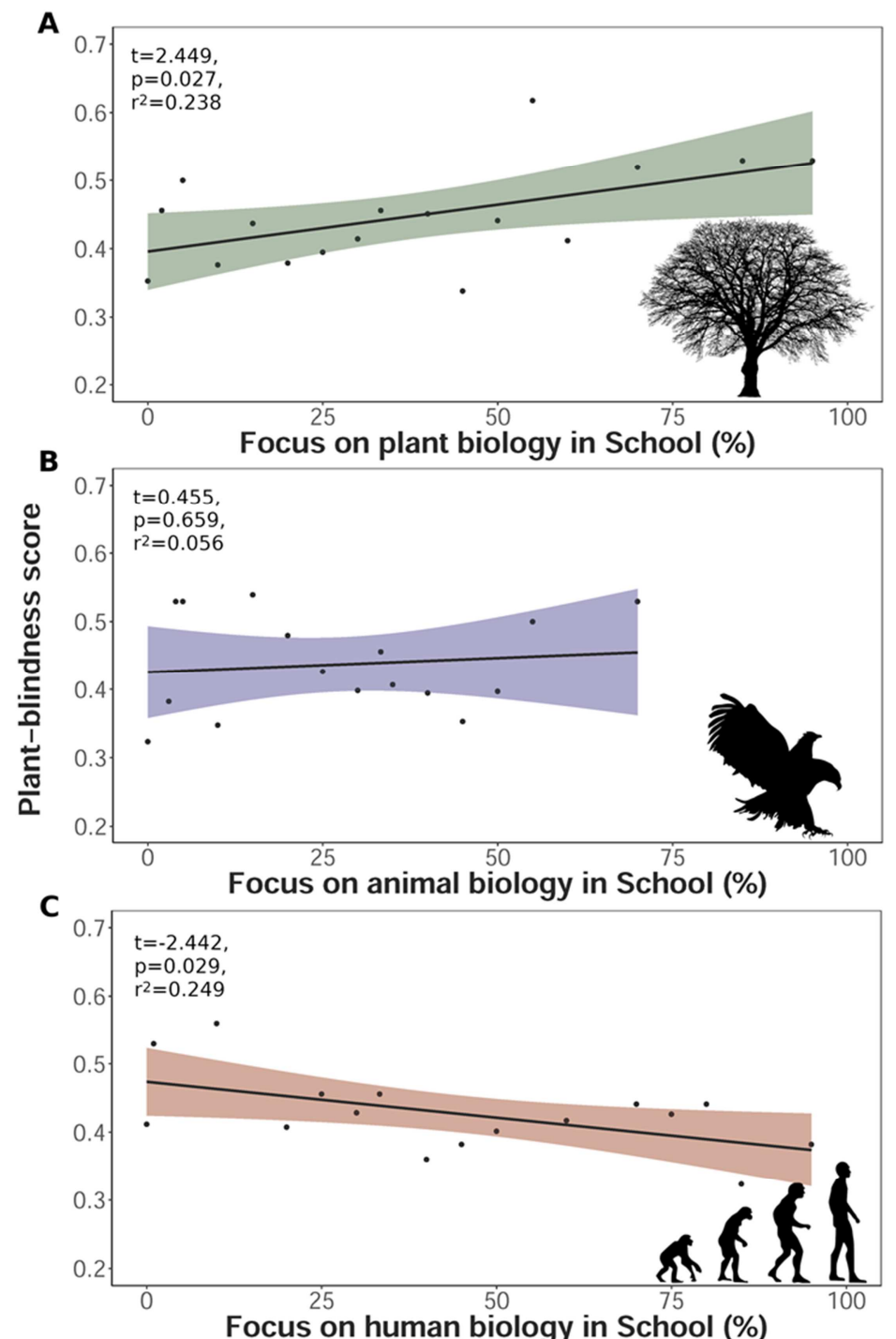

Figure 1. Correlation analysis of the mean plant-blindness score (PB) with the percentage of how much content was covered in schools, as perceived by the students, before they came to University on A) plant, B) animal and C) human biology. The PB score ranges from 0 to 1 , with 1 indicating a high 'awareness' of plants. 
When asking the students to provide the common names of four organisms (killer whale, daisy, robin and cherry tree; Appendix 1), 84.1\% of students identified the two animals correctly, whereas only $71 \%$ identified the plants correctly. Students particularly struggled to give the common name of the cherry tree $(60.2 \%$ of student responded correctly).

Most of the students surveyed had more of an interest in plants since they joined a university course in biology $(65.9 \%$; Table 3). In addition, most students agreed that since they started university, they had become more aware of plants (76.1\%).

Table 3. Answers to question nine in the questionnaire (Appendix 2): 'Since you started University, how has your perception towards plants changed'?

\begin{tabular}{lll}
\hline Answer & Responses & $\mathbf{\%}$ \\
\hline Not all & 22 & 25.0 \\
I have more of an interest in plants now & 58 & 65.9 \\
I have less of an interest in plants now & 8 & 9.1 \\
\hline
\end{tabular}

As a result of the plant-based content taught to them during level 5 and $6,30.6 \%$ of students specifically chose more plant-based modules in their final two years. Of those students who did not think that their exposure to plant related content at university made them choose more modules relevant to plants, $28.4 \%$ either stated that they a) never had an interest in plants, or that b) the content learned on plants had no effect on their module choice, with $3.4 \%$ of students believing that their interest towards plant biology decreased as a result of what they have been taught. The remaining $9.1 \%$ gave various other reasons that are summarised in Table 4.

Table 4. Additional reasons students identified for why their exposure to plants at university level education encouraged them to choose less plant related modules.

\begin{tabular}{|c|c|}
\hline Question & Answers \\
\hline $\begin{array}{l}\text { Has your } \\
\text { exposure to plants } \\
\text { made you chose } \\
\text { more modules } \\
\text { relevant to } \\
\text { plants? }\end{array}$ & $\begin{array}{l}\text { 1) I did not have enough module choice to pick plant } \\
\text { relationships. } \\
\text { 2) I prefer human genetics and modules related to that. } \\
\text { 3) I am more interested in humans, so want to focus } \\
\text { my modules towards that. } \\
\text { 4) I find it too difficult. }\end{array}$ \\
\hline
\end{tabular}

\section{Discussion}

Transition is a process of the coordination and continuation of an activity during movement from one setting/level into another [22]. In HE this involves the facilitation of student engagement into a specialised subject discipline from when they leave school [23]; which helps them to develop practices of the heart and the mind that enlarges their capacity for continuous learning and development when they graduate [24, 25]. When students come to university to study disciplines such as biology, it is expected that their interest and basic understanding of the subject is already developed. However, the degree of interest and knowledge can vary substantially between individuals from within the same cohort, and has likely been shaped by the students' experience and exposure to that particular subject discipline prior to joining university [26]. Hence, it is important for university educators to know and appreciate, not only the degree of knowledge students have of their specific discipline, but also be aware of how they perceive the subject, and their sub-disciplines when they start and develop through university. Pupils in UK schools are taught at an early age that biology is divided into three main subdisciplines; namely Human, Animal and Plant Biology [14]. However, because throughout their early educational development (i.e. year 5-18) the degree of sub-discipline content taught to them varies substantially (e.g. only $20 \%$ of content focuses on plants at Stage 3 and 4), pupils in the UK are not given an opportunity to equally develop an interest across all biology disciplines. For example, our study found that over $65 \%$ of students surveyed had developed more of an interest in plants since they started university, and that in over $30 \%$ of students the exposure to plant related content had made them actively select more modules relevant to these areas over subsequent years. These are intriguing numbers and it encourages consideration of how they would compare to students that have more exposure to plant related content pre-university, and whether this would aid the transition into plant related programmes and modules during university education.

The growing evidence of increased PB in society [11, 27], coupled, at least in the UK, with the evidence of a bias in early education towards a zoocentric curriculum, strongly suggests that $\mathrm{PB}$ is at least to some extent driven by government educational policy. Our study identified a weak but significant positive correlation between the amount of content students perceived to have covered on plant biology in school and their current awareness of plants. Moreover, we also found a weak negative correlation between the amount of content students perceived to have covered on human biology in school and their current awareness of plants. Although this is not a causal relationship, it still strongly suggests that the 'degree' of PB in students at university is influenced by the type of biological content they covered at school. However, blaming the educational system on the increasing rise in $\mathrm{PB}$ would form an incomplete discussion [28]. For example, Balas and Momsen [7] demonstrated with a visual experiment that the human perception of plants and animals differs. They found that plant images were less reliably detected in an image sequence than animals, suggesting that PB may result from differences in how attention is deployed towards plants (i.e. it is more difficult to notice plants). The exact reasons for their observations are still not clear, but it could be argued that when different plants grow together then they are perceived to look more similar (i.e. green), compared to animals from the same habitat that can differ significantly in appearance. However, it could simply be that the response to plants by human perception is more delayed than responses to animals [29]. The last point could be linked to an evolutionary response of human to fear [30]. For example, Bennett-Levy and Marteau [31] found that human preparedness to fear is much stronger 
towards animals with certain characteristics (e.g. a snake versus a rabbit). They suggested that the fear of certain animals over others is a result of the fear-evoked perceptual properties and discrepancies from the human form. If that is the case, plants would score very low in an experiment of fear where animals are included. It is likely that at least one of the contributing drivers of $\mathrm{PB}$ comes from our evolutionary adaptation to fear animals more than plants. Given that plants cannot run away [32], it is reasonable to argue that a higher fear response towards animals in humans is evolutionary more advantageous, hence why plants could be perceived as less important. For example, we found that students in our survey identified common animals more accurately compared to common plants, an observation that has been reported previously [4].

So how do educators counteract PB in schools and at universities? And how can we make plants more attractive to students? To help to answer these questions we summarised the responses of our 88 surveyed students using the responses given from when they were asked to identify new ways to improve plant awareness (Table 5). The responses fell into three main categories, namely 'contact with plants', 'theoretical knowledge' and 'access to information' (Table 5). The top three responses were; (i) students would like more plant related activities outside of the classroom, (ii) more knowledge on the use of plants (e.g. medicinal, biotechnological and food production), and (iii) some 'handson' experience in growing their own plants (Table 5). Interestingly, research conducted by Krüger and Burmester [33] in Germany found that the relationship between the individual and the 'use' of a plant is an important consideration by students, particularly when they attempt to classify and relate to them. Therefore, being able to identify and classify seems to be an important skill for students [4]. In addition, Pany [34] found that the relatedness to 'plant-use' is also strongly influenced by the type of plant, or plant group, used. He concluded that medicinal plants and stimulant herbal drugs, used within an educational context are especially suitable in the battle against PB, as students showed an above-average interest to these groups. Additionally, giving students the opportunity to grow their own plant(s) and engage more actively with plants in their natural environment, could further help to improve their consciousness and relationship towards them. This has been demonstrated by garden-based education projects in Brooklyn, U.S. [35]. Interestingly, our study did not find a difference in PB between students that had a garden when they grew up and those that did not. However, this could be because having a garden does not simply mean that plants are actively been engaged with by the owners [36]. It is the 'active engagement' in working with plants that appears to be sought by students and could help to combat PB.

Table 5. Responses of students surveyed when they were asked how they think plants can be made more attractive to them. The different responses were divided into three general categories.

\begin{tabular}{lll}
\hline Category & Responses & Frequency of responses \\
\hline Contact with plants & Take us out of the classroom. \\
Theoretical knowledge & Tell us more about plant uses. \\
Contact with plants & Let us grow our own plants. & 17 \\
Theoretical knowledge & Tell us more about current issues that affect the future (e.g. climate change and plants). \\
Theoretical knowledge & Tell us more about plant-animal interactions. \\
Theoretical knowledge & Tell us more about plant related careers. \\
Access to information & Simplify the taught content. \\
Theoretical knowledge & Tell us more about exotic/interesting/colourful plants. \\
Access to information & Offer more plant-based modules. \\
Theoretical knowledge & Tell us more about plant diseases. \\
Theoretical knowledge & Tell us more about different groups of plants. \\
Theoretical knowledge & Tell us more about how plants work. \\
Contact with plants & Engage us more in research. \\
NA & I don't know. \\
& Total \\
\hline
\end{tabular}

Designing a national curriculum that could encapsulate more plant-based knowledge and further enable students to actively work with plants at school, would help to improve the transition of students to plant based university courses. This will also help to foster a more balanced sub-discipline subject intake across biology degree programmes. Our study has shown that if you give students the opportunity to engage in the study of plants, they often will. Here we identify, what we believe are six main areas that can be improved at a school and university level to combat PB (Table 6).

In a classroom, the teachers' passion and enthusiasm towards a particular subject discipline has been shown to be the most powerful predictor of students' intrinsic motivation and vitality [37]. An online review of current biology teacher training programmes in the UK, releveled that teachers struggle to find a component of the current curriculum that allows them to develop a more passionate relationship towards education about plants. This could be improved by simply providing additional examples on biological processes and functions using plant-model systems, instead of animal or human based systems [34]. Encouragingly, free support to integrate more plant-model systems into the school curriculum are already available through the Science and Plants for School initiative (SAPS; www.saps.org.uk).

When plants do feature in the current UK school curriculum it is heavily saturated with theories linked to photosynthesis $(30-35 \%$; [14]). It has been shown that although many students understand the concept of 
photosynthesis, many are not aware of the consequences of energy transfer and storage, and/or how water links other physical and chemical process, such as methods of water uptake and respiration [38]. Perhaps students find it difficult to relate to the concept of photosynthesis, and due to the repetitive nature of photosynthesis in the curriculum, end up losing interest towards plants altogether. Teachers should, therefore, put more focus on the application of plants within their classes, and increase the amount hands-on experience in plant biology (Table 6). At University level, lecturers could improve plant awareness amongst students by incorporating more subject content that is relevant to plant application and provide students with a guide to possible plant related careers (Table 6).

Table 6. Six key proposed areas that need to be developed at school and university to improve plant awareness amongst students.

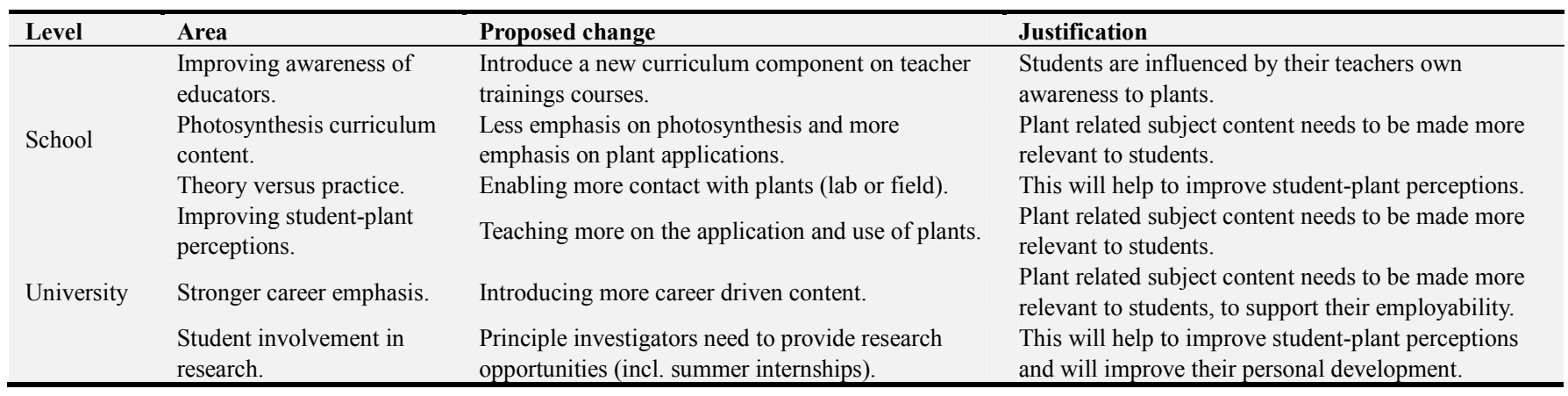

\section{Conclusion}

In conclusion, this study provides for the first time, insight into the possible underlying driver of $\mathrm{PB}$ in young UK adults. It found evidence that $\mathrm{PB}$ is, at least to some extent, driven by underrepresentation of plant related curriculum content in schools. Most surveyed students in this study (over $65 \%$ ) believe that since they have started university, they are more aware of plants. Furthermore, over $30 \%$ of surveyed students believe that the plant content they were taught since they started University has made them more likely to choose plant related modules. This clearly suggests that there is an inherent interest in plants by young people, but that this interest and passion is strongly underdeveloped and requires careful nurturing. We proposed six areas that need to be developed at school and university to improve plant awareness and tackle the current trend of increased PB.

\section{Acknowledgements}

We thank Dr. Damien Litchfield from the Physiology Department at Edge Hill University (EHU) for the advice and feedback on the study quiz and questionnaire. We also thank Prof. Paul Ashton for his support during the data collection.

\section{References}

[1] Rosch E, Mervis CB, Gray WD, Johnson DM, Boyes-Braem P. Basic objects in natural categories. CPsy. 1976; 8 (3): 382-439.

[2] Berlin B. Ethnobiological classification: Principles of categorization of plants and animals in traditional societies: Princeton University Press; 2014.

[3] Balding M, Williams KJ. Plant blindness and the implications for plant conservation. Conservation Biology. 2016; 30 (6):
1192-9.

[4] Schussler EE, Olzak LA. It's not easy being green: student recall of plant and animal images. J Biol Educ. 2008; 42 (3): $112-9$.

[5] Wandersee JH, Schussler EE. Preventing plant blindness. The American Biology Teacher. 1999; 61 (2): 82-6.

[6] Hershey DR. A Historical Perspective on Problems in Botany Teaching. The American Biology Teacher. 1996; 58 (6): 340-7.

[7] Balas B, Momsen JL. Attention "blinks" differently for plants and animals. CBE life sciences education. 2014; 13 (3): 43743.

[8] Fančovičová J, Prokop P. Plants have a chance: outdoor educational programmes alter students' knowledge and attitudes towards plants. Environmental Education Research. 2011; 17 (4): 537-51.

[9] Mace GM, Barrett M, Burgess ND, Cornell SE, Freeman R, Grooten M, et al. Aiming higher to bend the curve of biodiversity loss. Nature Sustainability. 2018; 1 (9): 44851 .

[10] Larson LR, Szczytko R, Bowers EP, Stephens LE, Stevenson KT, Floyd MF. Outdoor Time, Screen Time, and Connection to Nature: Troubling Trends Among Rural Youth? Environment and Behavior. 2018; 0 (0): 0013916518806686.

[11] Frisch JK, Unwin MM, Saunders GW. Name That Plant! Overcoming Plant Blindness and Developing a Sense of Place Using Science and Environmental Education. In: Bodzin AM, Shiner Klein B, Weaver S, editors. The Inclusion of Environmental Education in Science Teacher Education. Dordrecht: Springer Netherlands; 2010. p. 143-57.

[12] McDonough MacKenzie C, Kuebbing S, Barak RS, Bletz M, Dudney J, McGill BM, et al. We do not want to "cure plant blindness" we want to grow plant love. Plants, People, Planet. 2019; 1 (3): 139-41.

[13] Jose SB, Wu C-H, Kamoun S. Overcoming plant blindness in science, education, and society. PLANTS, PEOPLE, PLANET. 2019; 1 (3): 169-72. 
[14] GOV. National curriculum. In: Education Df, editor. https://www.gov.uk/government/collections/nationalcurriculum: GOV.uk; 2014.

[15] GOV. GCE AS and A level subject content for science. https://www.gov.uk/government/publications/gce-as-and-alevel-for-science: Department for Education 2014 9th April.

[16] GOV. Statutory guidance - National curriculum in England: science programmes of study https://www.gov.uk/government/publications/nationalcurriculum-in-england-science-programmes-of-study/nationalcurriculum-in-england-science-programmes-of-study: Department for Eduction 2015 [May 2015].

[17] UKPSF. UK Plant Science: Current status \& future challenges. https://www.rsb.org.uk/images/pdf/UK_Plant_ScienceCurrent_status_and_future_challenges.pdf: Society of Biology; 2016.

[18] UCAS. 2018 cycle application figures. https://www.ucas.com/corporate/data-and-analysis/ucasundergraduate-releases/2018-cycle-applicant-figures-januarydeadline: Universities and Colleges Admissions Service; 2018.

[19] CEI, UW. The Uptake of Plant Sciences in the UK - A Research Project. https://www.gatsby.org.uk/uploads/plantscience/reports/pdf/cei-uptake-of-plant-science-in-uk-feb09.pdf: The Centre for Education and Industry and University of Warwick 2009.

[20] EHU. Edge Hill University code of practice for the conduct of research https://www.edgehill.ac.uk/documents/code-ofpractice-for-the-conduct-of-research/: Edge Hill University 2016.

[21] R Developing Core Team. R: a language and environment for statistical computing 3.1.2 ed. R Foundation for Statistical Computing, Vienna, Austria. URL http://www.R-project.org/. R Foundation for Statistical Computing; 2017.

[22] Landzberg MJ, Gurvitz M. Transition Education: Formative Steps, in Need of Direction. J Am Coll Cardiol. 2018; 71 (16): 1778-80.

[23] Kift SM, Nelson KJ, Clarke JA. Transition pedagogy: a third generation approach to FYE: a case study of policy and practice for the higher education sector. The International Journal of the First Year in Higher Education. 2010; 1 (1): 1-20.

[24] Shulman LS. Making Differences: A Table of Learning. Change: The Magazine of Higher Learning. 2002; 34 (6): 3644.

[25] Carini RM, Kuh GD, Klein SP. Student Engagement and
Student Learning: Testing the Linkages*. Research in Higher Education. 2006; 47 (1): 1-32.

[26] Klein SB. Learning: Principles and applications: Sage Publications; 2018.

[27] Sundberg M, Antlfinger AE, Ellstrand NC, Mickle JE, Douglas AW, Darnowski DW. Plant blindness:" We have met the enemy and he is us. Plant Science Bulletin. 2002; 48 (3).

[28] Wandersee JH, Schussler EE. Toward a Theory of Plant Blindness. Plant Science Bulletin. 2001; 47 (1).

[29] Vul E, Nieuwenstein M, Kanwisher N. Temporal selection is suppressed, delayed, and diffused during the attentional blink. Psychol Sci. 2008; 19 (1): 55-61.

[30] LeDoux JE. Chapter 21 - Evolution of human emotion: A view through fear. In: Hofman MA, Falk D, editors. Prog Brain Res. 195: Elsevier; 2012. p. 431-42.

[31] Bennett-Levy J, Marteau T. Fear of animals: What is prepared? BJP. 1984; 75 (1): 37-42.

[32] Karban R, Orrock JL, Preisser EL, Sih A. A comparison of plants and animals in their responses to risk of consumption. Curr Opin Plant Biol. 2016; 32: 1-8.

[33] Krüger D, Burmester A. Wie Schüler Pflanzen ordnen. Zeitschrift für Didaktik der Naturwissenschaften. 2005; 11: 85-102.

[34] Pany P. Students' interest in useful plants: A potential key to counteract plant blindness. Plant Science Bulletin. 2014; 60 (1): $18-27$.

[35] Libman K. Growing Youth Growing Food: How Vegetable Gardening Influences Young People's Food Consciousness and Eating Habits. Applied Environmental Education \& Communication. 2007; 6 (1): 87-95.

[36] Cameron RWF, Blanuša T, Taylor JE, Salisbury A, Halstead AJ, Henricot B, et al. The domestic garden - Its contribution to urban green infrastructure. Urban Forestry \& Urban Greening. 2012; 11 (2): 129-37.

[37] Patrick BC, Hisley J, Kempler T. "What's Everybody So Excited About?": The Effects of Teacher Enthusiasm on Student Intrinsic Motivation and Vitality. The Journal of Experimental Education. 2000; 68 (3): 217-36.

[38] Hazel E, Prosser M. First-Year University Students' Understanding of Photosynthesis, Their Study Strategies \& Learning Context. The American Biology Teacher. 1994; 56 (5): 274-9. 